\title{
Enunciación
}

http://revistas.udistrital.edu.co/ojs/index.php/enunc

\section{Escritura(s) y modos de subjetivación: del ciudadano moderno a la subjetividad juvenil contemporánea}

\section{Writing(s) and subjectivation: From the modern citizen to the contemporary young subjectivity}

\author{
Mónica María Bermúdez Grajales ${ }^{1}$
}

\begin{abstract}
Para citar este artículo: Bermúdez, M. M. (2015). Escritura(s) y modos de subjetivación: del ciudadano moderno a la subjetividad
\end{abstract} juvenil contemporánea. Enunciación, 20(1), pp. 56-67.

Recibido: 06-mayo-2015 / Aprobado: 23-junio-2015

\section{Resumen}

El presente texto plantea el lugar preponderante que tuvo la escritura en la configuración política del ciudadano moderno. Prácticas escriturales concebidas para el desarrollo de la autonomía, el autocontrol y la domesticación de las pasiones fueron algunas de las aristas que promovieron la construcción de un sujeto racional que pudiera participar en la esfera pública y en las actividades propuestas por el Estado-nación. Hoy, el sentido de la escritura moderna ha variado: paralelamente a las transiciones económicas, sociales y tecnológicas están sugiriendo otros modos de escribir. De hecho, no requerimos de aquel tipo de escritura como única condición para la participación política, pues hoy los movimientos sociales y las interacciones comunicativas-digitales de muchos jóvenes con sus narrativas hipertextuales nos muestran una reivindicación de lo oral, lo sonoro y lo icónico como trámite de una subjetividad política que no deviene racional en el sentido moderno, sino nómada, vernácula y sensible.

Palabras clave: modernidad, subjetividad juvenil, tecnologías digitales e hipertextos.

\begin{abstract}
The present text is related to the preponderant status that writing occupied in the political configuration of the modern citizen. Writing practices conceived for development of autonomy, self-control and domestication of passions were some of the ideas that promoted the construction of a rational individual who was able to participate in the public arena and activities conceived by the Nation-State. Nowadays, the meaning of modern writing has varied. Other writing styles are being developed in parallel to the economic, social and technological transitions. In fact, we do not require such a kind of modern writing as the only condition for the political participation. At present, social movements and the communicative and digital interactions of many youngsters, and their hyper textual narratives, show us a vindication of the oral, resounding and iconic as process of a political subjectivity that does not become a rational one in the modern sense but in a nomadic, vernacular and sensitive one.
\end{abstract}

Keywords: Modern life, youth subjectivity, digital technologies, hyper texts.

1 Magíster en Educación de la Universidad de Antioquia; estudiante del Doctorado Interinstitucional, en el grupo Educación y Cultura Política de la Universidad Pedagógica Nacional. Profesora del Departamento de Formación de la Pontificia Universidad Javeriana, Bogotá (Colombia). Correo electrónico: mmbermudez@javeriana.edu.co 


\section{CONTEXTO}

Las percepciones humanas y estudios en general dan cuenta de transformaciones en los nuevos tiempos que, mayormente, se visibilizan en las actuaciones que la subjetividad produce hoy. Se trata de cambios que se hacen sensibles y en ocasiones explícitos por los modos de relación y configuración individual a partir de la mediación de algunos dispositivos socioculturales que hacen parte de ellos y que resultan muy distintos si los examinamos en paralelo con las prácticas de fabricación subjetiva que operaron en la modernidad. Estos cambios consisten en subjetivaciones en las que la disciplina y el encierro no son las técnicas predominantes en la formación de las personas, pues ahora la subjetividad se procesa a través de la flexibilidad, la velocidad, el consumo y la creación narcisista. Estos rasgos encuentran su origen en lo económico, en el poder hegemónico de unas clases sobre otras y en la idealización de las naciones, que ahora buscan parecerse entre sí bajo la lógica de una globalización que se vuelve subjetivante en las prácticas que los sujetos construyen hoy (Martín-Barbero, 2003b).

Como lo expresa Mejía (2004), la producción subjetiva se amarra a las formaciones sociales y culturales de cada época. Son las estructuras biopolíticas las que originan en los sujetos, incluso antes de nacer, los significados identitarios de los territorios, los discursos, las prácticas y las representaciones de mundo como extensiones de lo que se requiere para el logro de los fines que se persiguen. Es así como en la sociedad moderna el sujeto idealizado tenía que ser obediente, disciplinado, dócil y productivo, además de blanco, varón, heterosexual e ilustrado (Castro-Gómez, 2009; Escobar, 2012). Y, para lograrlo, el Estado-nación se valió de algunos artilugios como los libros, los manuales de buen comportamiento y las prácticas escriturales en solitario como condiciones para fortalecer el juicio y la opinión pública, tan necesarios para la supervivencia de la política estatal y para la visibilización del ciudadano moderno (González, 1994).

Esas prácticas de lectura y escritura tenían como intención domesticar al salvaje (Sibilia, 2012; González, 1994), restarle emoción y sensibilidad a su comportamiento a través de la razón, la acumulación de conocimiento y la escritura de diarios personales en los que los sujetos, en su espacio íntimo, se evaluaban a sí mismos ${ }^{2}$, en una especie de vigilancia del yo con el yo, y cuyo fin tenía que ser la reflexión y la introspección como formas que, de algún modo, predecían el cambio y la cualificación del comportamiento moral en ámbitos sociales-públicos.

Como veremos más adelante, la escuela fue aliada y militante de este proyecto moderno, pues, al fungir como extensión de la estructura social hegemónica, propiciaba en los sujetos el disciplinamiento del cuerpo y el moldeamiento de una mente racional a partir de prácticas rutinarias y mecánicas de lectura y escritura, en las que se privilegiaba -mayormente- la repetición de letras, la memorización de frases, las planas de sílabas, las categorías gramaticales y las lecturas que reforzaban el amor a la patria y los deberes para con el Estado-nación. La escuela ayudó a tallar al nuevo ciudadano, lo capacitó para el trabajo, lo ayudó a gobernar sus emociones, construyó un lector y escritor subjetivado a partir de la consigna "la letra con sangre entra" y le entregó a la sociedad un sujeto racional-ilustrado, digno de la esfera pública (Sibilia, 2012; Herrera, 2013).

Pudiéramos decir que, actualmente, la escritura racional como condición sine qua non del sujeto político ha perdido parte del monopolio que poseía en la modernidad. Su mediación para la construcción de un cuerpo civilizado y moralmente correcto se ha desvanecido. Tal desvanecimiento

2 Este sentido de escritura solitaria, de evaluación moral-yoica, es diferente a lo que planteó Foucault (1996) cuando se refirió a la escritura como mediación para ocuparse de sí mismo. Tal referencia foucaultiana es traída de los griegos, para los cuales la escritura debía ser un proceso de meditación, de reevaluación de las obras subjetivas realizadas en el día. 
se ha derivado de dos fenómenos. Uno de ellos han sido las protestas y resistencias que, desde tiempo atrás, estamos presenciando: movimientos sociales y grupos de sujetos que, indignados por la explotación laboral y por la falta de reconocimiento de la diferencia, encontraron en los panfletos, grafitis y pasacalles, entre muchas otras formas de expresión, maneras de mostrar el malestar provocado por las injusticias que ven en su sociedad. Con dichas producciones escritas se agudizó la lucha política, con la que se lograron el cambio de leyes, algunas interpelaciones a reformas estatales y nuevos derechos (Rama, 2004).

Un segundo fenómeno es el producido por el uso de tecnologías digitales, especialmente en las generaciones más jóvenes, para las que los lenguajes hipertextuales, la imagen y la significación de una cultura visual componen el espacio comunicativo, y se constituyen en otra figura de la razón, como lo ha expresado Martín-Barbero (2003b). Se trata de lenguajes que no son enseñados por la escuela, sino que son aprendidos en las interacciones cotidianas que llevan a cabo los sujetos y desde los que se construye una agencia particular de lo político ${ }^{3}$.

A partir del segundo fenómeno, consideramos que las escrituras digitales son las que están transformando, principalmente, los significados modernos que fueron asignados a la producción escrita y a los modos en que las personas debían subjetivarse políticamente a partir de ella. Sabemos que son escrituras jalonadas por una lógica de mercado, es decir, por una racionalidad económica cuya apuesta reside en producir consumidores, modular afectos, deseos y sensaciones (Castro-Gómez, 2009); pero también nos pueden mostrar subjetivaciones políticas por las relaciones intensas que los jóvenes tienen con ellas, en las que una autorrealización opuesta a una lógica

3 No obstante, la escuela no quiere reconocer lo que está pasando y continúa fiel a una cultura alfabética en la que la repetición de letras, la memorización de reglas gramaticales y la enseñanza de estructuras de géneros discursivos componen el conocimiento letrado para unas subjetividades que cada vez más se sumergen en los mundos virtuales. dominante y un despliegue de lo comunicativo como forma de significar la existencia pueden ser, entre otras más, las invenciones subjetivas de este tiempo.

Lo anterior nos permitirá expresar que el ciudadano moderno ha decaído, su legislador —el Estado- está agonizante 4 . Debido a esta agonía, creada en parte por la globalización y por la alianza con el mercado ${ }^{5}$, no queda otra opción que desplegar las posibilidades y significaciones que una subjetividad política "desde abajo" puede producir, en procura de la supervivencia que le exige la vida misma. Por ello, destacamos, a partir de las prácticas juveniles contemporáneas, estas características y acciones en las que la escritura, sobre todo digital, expresa modos particulares de sentir y producir la política.

Agregado a lo anterior, nos interesa tensionar un diálogo con la escuela y con una pedagogía del lenguaje, en tanto deseamos insistir en la necesidad de resignificar unas prácticas de escritura que sean más diversas y plurales, que puedan vincularse más con los sentires de los estudiantes, a sus proyectos, a sus formas de vida y a las posibilidades de creación y narrativa; prácticas en las que no necesariamente la gramática y formalidad lingüística sean los anclajes de la enseñanza. Como veremos más adelante, queremos una

4 Esta agonía se manifiesta, por ejemplo, a partir de los derechos de los ciudadanos que quedan limitados a las posibilidades económicas de las personas: la educación y la salud, que son derechos fundamentales para todos, quedan como servicios a merced de los costos que cada quien puede pagar por obtenerlos. Hoy lo que vemos, a diferencia de la sociedad industrial, es que el Estado se desentiende de las responsabilidades que debe tener con sus ciudadanos, pues sus instituciones sociales cada vez más se privatizan, lo que da lugar a las luchas políticas que surgen del malestar y la indignación que tales sucesos generan.

5 Articulado al fenómeno de la globalización, o globalismo, como lo Ilama Beck, citado por García Canclini (2008), está el deslinde lo que lo que económicamente se presenta, y con ello, la estructura de un sistema (económico) que incide en las formas de comunicación, ciudadanía, subjetividad y cultura política, entre otros. De esta manera, "[...] Las estrategias globales de las empresas y los Estados configuran máquinas segregantes y dispersadoras. Sus políticas de 'flexibilización laboral' producen desafiliación a sindicatos, migraciones masivas dramáticas, mercados informales, en algunos casos conectados por redes de corrupción y lumpenización" (p. 14). 
escritura más relacionada con la lucha política del sí mismo y como experiencia en propósitos de participación y cooperación colectiva. Nos interesan las producciones escritas que pasan por imágenes, sonidos, videos; las escrituras hipertextuales que pueden identificar a las personas con lo que son, con sus historias y deseos; las escrituras que acercan, animan, liberan y empoderan, que no sean tan rígidas como lo fueron en la modernidad. Necesitamos comprender que hoy la escritura deviene otra, y es porque los sujetos son otros, como dice Serres (2013), pulgarcitos cuyas escrituras brotan de los pulgares y dejan huellas por donde pasan.

Este escrito se compone de tres apartados. El primero se ocupa de explicitar las relaciones de la escritura con la configuración del ciudadano moderno, desde tres ámbitos: inicialmente, se plantea la Ilustración como movimiento o tendencia kantiana en la que el desarrollo de la razón y la autonomía derivadas de las prácticas lectoras y escritoras construyeron las coordenadas sociales y culturales de intervención política. Luego aparece la escuela como espacio privilegiado para formatear los cuerpos modernos, sobre todo los infantiles, a través de métodos repetitivos y mecánicos de enseñanza de la lectura y la escritura. Y, por último, surge el espacio íntimo como lugar de empoderamiento subjetivo logrado a partir de las lecturas y escrituras solitarias, en las que la novela y los diarios personales ocuparon un lugar central.

El segundo apartado da cuenta de las escrituras digitales como expresiones de la subjetividad juvenil contemporánea. A través de ellas se precisan algunas características de la composición hipertextual, las cuales, a su vez, desplazan representaciones secuenciales-lineales de la escritura para significarla en una textura hecha de fragmentos, nodos y links. Para cerrar, se presentan, a modo de epílogo, algunas implicaciones para la escuela y para una pedagogía del lenguaje en la que la escritura digital como experiencia individual y colectiva puede ser parte de su repertorio formativo.

\section{MODERNIDAD Y ESCRITURA}

Uno de los intereses de este apartado es mostrar el juego político y social que se construyó a partir de la escritura, entendida como dispositivo de poder, para los sujetos de la modernidad. Este juego se configuró a partir de tres ámbitos: el proyecto de la llustración, la escuela y el espacio intimo, los cuales funcionaban de modo casi independiente, aunque las implicaciones de cada uno repercutían en el diseño del sujeto ideal de la época. El primero de ellos, el proyecto de la Ilustración, con su intención, a través de la escritura, de racionalizar el cuerpo y la mente, construyó uno de los engranajes más fuertes de la modernidad. Este movimiento impactó fuertemente en las clases sociales, profundizó las diferencias entre ellas y declaró de manera más abierta y agresiva la separación social entre sujetos burgueses y el pueblo, compuesto mayormente por obreros y campesinos (Rama, 2004).

Un segundo ámbito lo ocupó la escuela, que se dio a la labor de moralizar y civilizar a sus estudiantes a través de los manuales de urbanidad (González, 1994) y de la mecanización de lecturas y escrituras en las que la pronunciación del fonema y el dibujo de las letras ocuparon un lugar central en la enseñanza. Un tercer y último ámbito lo configuraron las prácticas de escritura y lectura en solitario, en el recinto privado, con las cuales se fortalecía el juicio y la razón, y que luego eran socializados en los espacios públicos (Chartier, 2006). Veamos cada uno de estos escenarios.

\subsection{La Ilustración y su empeño por la autonomía} Como sabemos, el precursor de la Ilustración fue el filósofo alemán Immanuel Kant, para quien esta implica "el abandono por parte del hombre de una minoría de edad cuyo responsable es él mismo. Esta minoría de edad significa la incapacidad de servirse de su entendimiento sin verse guiado por algún otro" (2011, p. 83). El proyecto ilustrado, como bien lo expone Foucault (1993), surgió 
como salida de las ideas medievales en las que las explicaciones sobrenaturales y protecciones que los hombres se otorgaban a sí mismos dependían de algo o de alguien, lo cual permitía descargar en otros los miedos e inseguridades que por sí mismo no era capaz de resolver. Aquí la religión y la lectura de la Biblia fundaron deseos y procesos de subjetivación que derivaron en misticismos y en el fundamento de la culpa como pecado.

Para Kant, la forma de escapar a semejante misticismo era que cada hombre pensara por sí mismo, de forma autónoma, sin depender de nadie, y, sobre todo, que la voluntad fuese una decisión producida por el mismo hombre, no anclada en un estado de tutela (Foucault, 1993). Por ello, entonces, aparece la Ilustración, que inaugura un nuevo dios: la razón. Con esta, entendida como dominio de sí, el hombre escapaba del oscurantismo que originaba todo aquello que no estaba explicado por razones científicas (Yannuzzi, 2000); aquí la narración, las emociones y la superstición fueron invisibilizadas y obstruidas, porque el pensamiento y la autonomía se fundaban en el plano de la argumentación racional y científica ${ }^{6}$, por aquello de su carácter demostrativo.

A partir de la venia que la sociedad moderna ${ }^{7}$ le hace a la Ilustración se comienza un proceso de domesticación de la barbarie, de las emociones y pasiones (Herrera, 2013) que lleva consigo el hombre. Esto, por supuesto, favorecería una subjetividad dócil, obediente y productiva que idealizaba y creaba la sociedad moderna. No obstante, se requería de dispositivos o tecnologías que contribuyeran a dicho fin, que ayudaran a esculpir al nuevo ciudadano y lo hicieran más culto, civilizado e inteligente con los asuntos del Estado, y, sobre

6 Aquí resuena Descartes: "Pienso, luego existo". Este enunciado se convirtió en elemento fundamental para la constitución de la racionalidad occidental.

7 Inglaterra, Francia y Alemania fueron los países que, inicialmente, comenzaron con el desarrollo de las intenciones que la Ilustración proponía. Luego esta llegó a América Latina, donde la violencia física y simbólica sería más brutal, pues nuestros indígenas eran considerados más barbaros que un hombre blanco sin "razón". todo, más racional, para que pudiera deliberar y argumentar en los consensos de arbitraje estatal.

Es así como la lectura y la escritura fueron fundamentales en la construcción de este sujeto racional. Se trataba de lecturas y escrituras íntimas, alejadas del tumulto y de los cotorreos que producía la aglomeración de personas, con el fin de conseguir introspección y reflexión para que se favoreciera la objetivación del pensamiento. De ahí que, como lo expresa Walter Ong, "escribir y leer son actividades solitarias que hacen a la psique concentrarse en sí misma" (1987, p. 73).

Las lecturas y escrituras que mayormente se distribuyeron gracias a la imprenta, fenómeno que también promovió la Ilustración, fueron los libros de instrucción moral y las enciclopedias (Briggs y Burke, 2002). Estas últimas resultaron, en principio, asequibles solo para las clases burguesas, por los altos costos. No obstante, con ayuda también de la imprenta se produjeron versiones más económicas que luego los obreros y campesinos pudieron adquirir. El asunto aquí no fue meramente material, es decir, no solo se accedía al libro como producto industrial, sino que con su circulación y compra se llegaba al uso universal de la razón (Chartier, 2000), con el fin de que la fe, el prejuicio y la intuición desaparecieran, y los hombres - todos- pudieran ser libres, independientes de voluntad y encontrar un efugio a la minoría de edad.

Otra característica que se configuró con la lectura y la escritura como prácticas sociales y condiciones de participación política tuvo que ver con la construcción de dos espacios distintos pero profundamente relacionados: lo público y lo privado. El primero estaba anudado al ejercicio de la razón y las valoraciones (de carácter político) que eran socializadas en los escenarios públicos, donde los hombres exhibían los argumentos que los hacían parecer como sabios. Pero tales argumentos y juicios eran construidos en lo privado, el cual era considerado como terreno de los intereses particulares y domésticos (Chartier, 2000). De esta manera, el poder hegemónico moderno se valió de la lectura y la escritura para moldear lo cuerpos 
bárbaros en dóciles y civilizados, con el fin de robustecer el progreso, el desarrollo y los fines económicos de la sociedad industrial.

\subsection{La escuela como garante de razón y civilización}

Una de las funciones primordiales de la escuela moderna era la capacitación para el trabajo a través del desarrollo de las habilidades y las destrezas necesarias para la fuerza productiva que requería la sociedad industrial (Herrera, 2013). Pero, además de esto, se necesitaba entregarle a la nación sujetos civilizados, capaces de dominarse a sí mismos y de apartar las emociones y pasiones que obstaculizaban el uso de la razón. Los niños tenían que educarse, aprender conocimientos de corte científico a partir de los métodos educativos ${ }^{8}$ que los profesores impartían, para que cuando fueran adultos pudieran exponerse como ciudadanos honorables en el espacio público, pues se consideraba que carecían de pensamiento y eran cuerpos bárbaros faltos de domesticación (Sibilia, 2012).

Para civilizar a los "infelices" cuerpos, la escuela se valió de los manuales de urbanidad, a través de los cuales se le enseñaba al niño a comportarse en sociedad. Se trataba de escritos ortodoxos, dominantes y dogmáticos. Estos manuales promovían el "buen comportamiento" en las calles, en la iglesia e incluso en el hogar (González, 1994). La escuela, con su trabajo pedagógico, hacía que los estudiantes aprendieran de memoria estas lecciones morales, las practicaran en juegos simulados y escribieran planas para "asegurar" cierta internalización del comportamiento adecuado-civilizado que los niños debían exhibir como testimonio de su paso por la escuela9.

Así, la escuela cumplió con su papel disciplinante. Y con un agregado, una función lapidaria

8 Métodos de corte transmisionista en los que la voz del profesor, el libro, la memorización de la información y el cuerpo estático del estudiante componían las estrategias de aprendizaje (Avanzani, 2003). de la diferencia, de todo aquello que no correspondiera con el ideal moderno (Escobar, 2012; Herrera, 2013). En América Latina, por ejemplo, los niños afrodescendientes y pertenecientes a culturas indígenas sufrieron con más fuerza el azote domesticador de la escuela, pues eran considerados razas impuras, bárbaras, cuya piel resonaba con la esclavitud y la pobreza, y esa lengua "mal hablada" que evocaba las tareas pendientes de la colonización española.

Las prácticas de la lectura y la escritura ayudarían entonces a dotar a esas nuevas naciones de civilización, pues con estos mecanismos subjetivantes de autocontrol y desarrollo de la conciencia estarían contribuyendo a la producción del ciudadano moderno. Uno de los aspectos psicológicos que especialmente se promovió con los manuales de urbanidad fue la represión ${ }^{10}$ : la emoción, el Ilanto en público y la euforia se ocultaron para darle paso a la razón como prestigio del cuerpo moderno.

\subsection{El espacio íntimo de lectura y la escritura} El espacio configurado para el fortalecimiento del juicio y la opinión pública lo constituía el ámbito de lo privado (Béjar, 1988). Allí, en medio de la soledad y el aislamiento, el sujeto se sumergía en lecturas y escrituras que le permitirían cualificar y empoderar sus razonamientos, los cuales serían necesarios para su participación en el espacio público. Por ello, la imprenta jugó un papel crucial en la edad moderna, pues la distribución y circulación de libros estaba vinculada con la construcción de la conciencia política.

9 Una de las cuestiones que González (1994) plantea a partir de los manuales de urbanidad es que el sujeto explícito en ellos, sobre el cual recaían las recomendaciones del buen comportamiento, era un sujeto burgués. Estos manuales no presentaban sugerencias para el hombre campesino, gaucho, llanero; el único visible era el hombre rico, pudiente, visitador de teatros, organizador de cenas y con vestidos diversos según el lugar. Además de esto, se diferencian tenazmente comportamientos de hombres y mujeres, que, con su discurso, refuerzan una cultura patriarcal.

10 En este sentido el trabajo de Norbert Elias (1997) sobre el análisis del proceso civilizatorio y el psicoanálisis de Freud resuenan como ampliaciones fundamentales de estas referencias. 
La configuración de un escenario privado se produjo bajo el supuesto de que la escritura objetivaba el pensamiento, estructuraba la conciencia, fijaba las palabras, ordenaba las experiencias, propiciaba la lentitud y tenía como efecto subjetivante el autocontrol (Ong, 1987). Para conseguir dichos logros era necesario que los individuos se alejaran del bullicio y de la muchedumbre, con el fin de que la escritura lograra su cometido: "interiorizarse personalmente para que [afectara] los procesos de pensamiento" (Ong, 1987, p. 61). Así, la que perdía fuerza y se desvanecía lentamente era la oralidad. Esta se consideraba precaria y redundante, anudada al desorden, la ignorancia y la emoción, y con un elemento adicional: no permitía construir la distancia entre el conocer y lo conocido, asunto este que sí se lograba con la escritura (Ong, 1987).

La intimidad subjetivó al sujeto, lo hizo más individualista, más recogido en sí mismo, por los beneficios que ello le representaba: cultivo de lo interno y construcción de una voluntad más firme, dominada por él y no por otros (Béjar, 1988). Las novelas y los diarios personales se convertirían en los géneros más cultivados por ese sujeto retraído. Las novelas, porque serían la fuente del esparcimiento, y los diarios íntimos que, como narración de sí, contribuirían a la construcción moral de su fuero interno.

Ese espacio íntimo fue concebido más para los hombres que para las mujeres ${ }^{11}$. Como lo expresaba Virginia Woolf, "era impensable tener una habitación propia hasta el comienzo del siglo XIX, y mucho menos un espacio tranquilo o a prueba de ruidos, a menos que los padres fueran excepcionalmente ricos o muy nobles" (2012, p. 71). Recordemos que el sujeto moderno ideal fue varón, por ello, muchas mujeres quedaron marginadas a lo doméstico, a las labores del hogar y al cuidado de los hijos: "Las mujeres no han tenido ninguna oportunidad de escribir (...), por eso he puesto

11 Vale recordar que "La separación entre lo público y lo privado es el momento fundador del patriarcado" (Mouffe, 1999, p. 117). tanto énfasis en la cuestión del dinero y la habitación propia" (Woolf, 2012, p. 143).

Por lo anterior, vemos que las tecnologías de cada época funcionan con intereses particulares y ejercen acciones de poder sobre los propios sujetos. Acabamos de describir una escritura construida en el encierro, a través de la cual se pretendía fabricar cuerpos dóciles y civilizados. Ahora el asunto es otro, "en tiempos de globalización, el capitalismo exacerba una sociedad de control y requiere otro tipo de sujeción: más que la producción de los cuerpos de los trabajadores interesa la seducción de las mentes de los consumidores" (Escobar, 2012, p. 89). Se trata de prácticas que reconfiguran las relaciones con un Estado, que parece obnubilarse cada vez más por el mercado, y por un tipo de ciudadanía que se confunde, a la vez, con las demandas propuestas por el mismo capitalismo. Ahora el ciudadano se pierde en medio de una subjetividad consumista, en la que su proyección hacia la democracia está en los bienes que consume y en las posibilidades de endeudamiento que se le ofrecen, con el fin de que las aspiraciones del sujeto queden anudadas a lo que se adquiere materialmente.

Más allá de saber los gustos de las personas y valorar con ellos las tácticas de existencia, lo que el capitalismo actual pretende es crear lo que Castro-Gómez (2009), en diálogo con Lazzarato (2006), Ilama la "construcción de perfiles mayoritarios de subjetividad". Hoy la vida se gestiona a partir de la información que cada quien transmite a través de las tarjetas de crédito, las Ilamadas telefónicas, los microchips, las tarjetas de puntos, las encuestas virtuales, los mensajes de texto, entre otros (Sibilia, 2008; Castro-Gómez, 2009). Estos perfiles mayoritarios de subjetividad a los que se refiere Castro-Gómez (2009) son las configuraciones subjetivas, es decir, grupos de personas que se crean a partir del consumo y sus productos cuya implicación para la democracia y, en general, para las prácticas políticas será desgarradora, pues los que pueden y tienen acceso a ellos son los mismos sujetos reportados en las Ilamadas telefónicas, en 
las encuestas virtuales y en las tarjetas de puntos tan habituales en los supermercados.

Desde esta lógica, uno de los anclajes que utiliza el capitalismo actual son las máquinas informáticas, como las Ilama Lazzarato (2006), es decir, las tecnologías de la información y la comunicación (TIC), las cuales han sido creadas con intenciones que las mismas orientaciones y principios del modelo han producido. Las actuales tecnologías, las cuales se concentran en formatos digitales ${ }^{12}$, no son neutrales: en ellas se anudan fuerzas productivas, económicas, incluso bélicas ${ }^{13}$, así como relaciones de saber-poder que se gestan en las acciones sociales que los sujetos realizan con los artefactos.

Uno de los compromisos a los que nos convocan estos cambios socioculturales y técnicos se anuda a la indagación por las prácticas escriturales que hoy emergen, las cuales son producidas por los sujetos en marcos de consumo y en eventos comunicativos liderados por la industria del software. A diferencia de la sociedad moderna, hoy no interesa tanto aprender a escribir para participar políticamente en la esfera pública; lo que le interesa al mercado, que es casi el nuevo Estado, es la escritura como forma de consumo, como uso intenso de los dispositivos digitales producidos por las grandes multinacionales como Apple, Samsung, Nokia, Microsoft, Motorola, entre otras.

Si bien la escritura en la modernidad subjetivaba un cuerpo que se tornaba privado, solitario y civilizado, hoy la escritura digital de los jóvenes nos expresan que un yo está siendo construido desde un campo relacional y afectivo más intenso (Rueda, 2014); que sus impulsos y deseos pasan por nuevas formas "escritas", como los videos, imágenes o canciones, a la vez que comentan lo escrito por sus amigos, releen, escriben y vuelven a leer

12 Nos referimos a los diversos repertorios creados desde el computador y uso de internet: chat, correo electrónico, wikis, páginas web, blogs, redes sociales. Todos ellos configurados por bits y bytes.

13 Vale recordar que el origen de las tecnologías digitales se dio en este lugar de voluntad, discurso y poder. como en una práctica errante, queriendo siempre que pase algo.

\section{ESCRITURAS DIGITALES (VERNÁCULAS) COMO EXPRESIONES DE LA SUBJETIVIDAD JUVENIL CONTEMPORÁNEA}

Estas variaciones de la escritura que hoy tienen lugar en el lenguaje por cuenta del uso de las tecnologías de la hipertextualidad se manifiestan claramente a través de lo vernáculo, esto es, escrituras que aluden a usos derivados de lo personal, familiar y doméstico; son escrituras que dependen de la voluntad subjetiva de cada quien y no son reguladas por instituciones sociales (Cassany, 2012). Son, ante todo, producciones escritas vinculadas con el día a día, con la emergencia de lo humano y con la practicidad de lo que se quiere plasmar de forma escrita. Algunos ejemplos son los apuntes personales, los grafitis, las conversaciones en un chat, los comentarios en redes sociales-digitales, los tweets, entre otros.

Estas escrituras digitales (vernáculas) afectan los modos de subjetivación contemporánea, pues, a la vez que los sujetos producen dichas escrituras, estas producen un sujeto que se visibiliza más desde la exterioridad, desde la espectacularización de su yo (Sibilia, 2008), desde un deseo por comunicar lo que piensa en el instante, y por una alteridad que parece fortalecerse con la aceptación ("posteo") que otros hacen. Esto, por supuesto, dista mucho de lo que vimos del sujeto moderno, "dotado de vida interior, y volcado hacia dentro de sí mismo, que construía minuciosamente su yo en torno de un eje situado en las profundidades de su interioridad psicológica" (Sibilia, 2008, p. 62). Y dista, también, de prácticas lectoras y escritoras que otrora convocaban a un individuo enclaustrado en la privacidad de su hogar para interiorizar lo que se leía y exteriorizar lo que se escribía (Sibilia, 2008).

En un estado del arte que realizamos recientemente (Bermúdez, 2014), los estudios revisados en Colombia ${ }^{14}$ exponen que los espacios tecnomediados, como redes sociales, blogs y páginas 
web, son usados por los jóvenes como escenarios de producción expresiva, de comunicación y de afectación de las experiencias sociales, en las que se subjetivan políticamente a través de la libertad, la resistencia y la autocreación (Muñoz, 2007). A través de estos espacios tecnológicos tienen lugar situaciones que permiten a los sujetos movilizar las emociones que comunicativamente desean vincular con otros para fortalecer la lucha política y el cuidado de la vida como experiencia de sí. No se trata, según los estudios, de sobredimensionar estos espacios, sino, por el contrario, de visibilizar cómo la subjetividad se manifiesta hoy y cómo se narra corporal y verbalmente con co-ayuda de ellos.

La cultura digital, a la vez que rompe con tradiciones de la cultura letrada o alfabética, esto es, con las maneras lineales y secuenciales de leer y escribir, parece abrir paso a nuevas experiencias de invención subjetiva, en las que la apropiación de una semiótica hipertextual configura la expresión y la relación que los sujetos emprenden como formas vinculares con el mundo y con los otros. En este sentido, no se trata de hacer una apología de los dispositivos tecnológicos, sino más bien preguntarnos por las subjetividades que devienen, los lenguajes múltiples de escritura que se despliegan y las formas alternativas de la razón, ya que constituyen los nuevos dispositivos de subjetivación con los que hoy se ve desafiado un sujeto cuando decide interactuar con estas tecnologías.

Si antes la escritura era un proceso reflexivo, de autocontrol, de meditación privada, desde la cual se deseaba algo para que afectara la relación con el espacio público y el individuo no quedara excluido, hoy lo que buscan los jóvenes es una producción de experiencia conectada con el gusto, la amistad y el estado de ánimo, lo cual induce a la construcción de una escritura rizomática abierta, desmontable y susceptible de recibir constantes

14 Algunos de estos estudios fueron Daza (2011), Garcés (2011), Rueda (2011), Acosta y Maya (2012), Constain, Forero y Benavides (2012), Galindo (2012) y Rodríguez, X. (2013). modificaciones (Deleuze y Guattari, 1994). A través de esta escritura, los jóvenes configuran una política de la vida, aquella que, en palabras de Giddens (1995), deriva en una libertad de elección y en creaciones de formas de vida que promueven realizaciones del yo en circunstancias de interdependencia global, en un ambiente hipertextual siempre abierto y relacional.

En suma, las prácticas de los jóvenes nos manifiestan la provocación que les hace la industria cultural del software a partir de un abanico de opciones digitales (redes sociales, chats, videojuegos, entre otros), en las cuales se sumergen y comienzan a producir narrativas que inauguran afectos $y$ significados de vida. Nos muestran, también, un autodidactismo ${ }^{15}$ derivado de la exploración y la experimentación, para llevar a cabo los proyectos personales y colectivos. Aquí el péndulo entre sujeción y subjetivación se presenta de nuevo: por un lado, estos jóvenes nos exponen su apropiación de los dispositivos digitales, los cuales tienen un carácter hegemónico, pero, por otro, se empoderan a sí mismos, bajo los sentidos de relación que en nuestro tiempo está produciendo la escritura digital.

\section{A MODO DE EPÍLOGO}

Como vimos, en la modernidad, la escritura se convirtió en una práctica esencial para la participación y visibilización política de las personas en la esfera pública, pues su aprendizaje debía tener como efecto el autocontrol, el distanciamiento de sí, el fortalecimiento de los argumentos y la autonomía, condiciones que se consideraban fundamentales para poder votar, elegir un candidato, discutir un plan de gobierno, participar en los consensos, entre otras actividades de índole social y

15 Este es un aspecto que tensiona a la escuela actual con la moderna, y se logra a partir de las tecnologías digitales, con las que los jóvenes encontraron otras posibilidades para aprender y saber mucho más de lo que a veces ofrece la transmisión del profesor. No estamos haciendo una apología a ultranza de las tecnologías actuales, solo reconocemos cuestionamientos a la enseñanza del tiempo presente. 
política. Alcanzar la escritura no era fácil, dicha práctica estaba supeditada a procesos de dolor, ya que lo que se buscaba era domesticar el cuerpo y las pasiones con la supuesta racionalización que producía el hecho de escribir. No obstante, lo que los jóvenes contemporáneos nos divulgan, a partir de sus interacciones comunicativas-digitales, son escrituras emocionales e intuitivas que problematizan cada vez más el canon moderno, y que nos desafían, tanto a maestros como a investigadores, a descubrir las subjetivaciones presentes que se expresan en lenguajes simbólicos y narrativas hipertextuales.

Lo anterior nos revela que el cambio más sentido y significativo que se produce entre el proyecto moderno de los Estados nacionales y un proyecto posmoderno o posindustrial se relaciona con el paso del homo clausus ${ }^{16}$ al homo consumus, transición que subraya modificaciones en las prácticas políticas de los sujetos: si bien en la modernidad la ciudadanía era una condición y una práctica mucho más "sólida" en términos de las acciones emanadas de los derechos y deberes que las personas debían tener y cumplir, además del ejercicio de un Estado que desempeñaba un poder central sobre estas, hoy dicha noción se agrieta, adquiere otros matices, justamente por la articulación feroz que el Estado asume con el mercado.

Los jóvenes nos están mostrando una producción política que se relaciona más con la música, el performance y el arte, que propiamente con sus actividades tradicionales (Bermúdez, 2014). Estos sujetos recurren cada vez más a expresiones artísticas mediadas con tecnologías digitales para mostrar puntos de vista y luchas políticas que irrumpen en lugares cotidianos, con el objetivo de producir acontecimientos. De igual modo, hacen uso de lenguajes hipertextuales —videos, imágenes, animaciones, enlaces y mensajes de texto- que

16 Esta noción es abordada por Norbert Elias (1997) para referirse al hombre enclaustrado o encerrado producido por las técnicas de encierro promovidas en la sociedad moderna, y cuyas idealizaciones morales y políticas debían plegarse a la independencia, privacidad y civilización. contribuyen a traducir con más convencimiento la emoción, el afecto y la desazón de la experiencia vital del presente.

Las subjetividades juveniles que devienen hoy no son las mismas que la modernidad fundó, pues son más intensas en sus modos de comunicar, más dispersas, volátiles; se encuentran en un "sistema de paso" (Baricco, 2008) continuo y dejan huellas que se difuminan fácilmente. Por ello, desde esta visibilización que intenta ingresar al mundo del otro, del joven, del estudiante, aparece la escritura digital como posibilidad pedagógica de conocimiento, tanto de sí mismo como de los otros.

La intención comunicativa como invitación para que los estudiantes escriban no estaría dada para complacer al canon de la institución social, sino como forma propia de invención de sí que permite la construcción de conocimientos propios y compartidos. Es una escritura nuestra, que emana del fuero interno, que saca algo que no nos habíamos dicho (Larrosa, 2003). De igual modo, lo que nos parece llamativo de esta nueva cultura digital-letrada y que podemos extrapolar a nuestras aulas son los poderes que emergen: el compartir libros de forma instantánea, socializar la escritura, ampliar temas, fortalecer la curiosidad y significar las relaciones con los otros a partir de un juego de íconos son algunas posibilidades que rompen con el recorrido obligado de la secuencia del alfabeto (Piscitelli, 2009). Lo que vemos, también, es un poder para elegir y "ordenar" la acción, algo muy vinculado a la configuración del prosumer que nos desafía a una problematización de la enseñanza del lenguaje en la escuela.

\section{RECONOCIMIENTOS}

Este artículo es producto de la tesis doctoral "Escrituras digitales y modos de subjetivación política. Proximidades desde la subjetividad juvenil contemporánea", inscrita en el grupo de Educación y Cultura Política, en la línea Cibercultura y Educación, de la Universidad Pedagógica Nacional. La tesis es dirigida por la Dra. Rocío Rueda Ortiz. 


\section{REFERENCIAS}

Acosta, G. y Maya, C. (2012). Participación política en redes sociales: el caso de los grupos en Facebook. Medellín: Sello Editorial Universidad de Medellín.

Baricco, A. (2008). Los Bárbaros: ensayo sobre la mutación. Barcelona: Anagrama.

Béjar, H. (1988). El ámbito íntimo. Privacidad, individualismo y modernidad. Madrid: Alianza.

Bermúdez, M. (2014). Jóvenes, prácticas políticas y mediaciones tecnológicas. Una aproximación desde los estudios realizados en la última década (2000-2013). Estado del arte. Doctorado Interinstitucional en Educación, Universidad Pedagógica Nacional,

Briggs, A. y Burke, P. (2002). De Gutenberg a Internet. Madrid: Taurus.

Castro-Gómez, S. (2009). Noopolítica y sociedades de control: las subjetividades contemporáneas en Maurizio Lazzarato. En J. Martínez y F. Neira (Eds.). Cátedra Lasallista: Miradas sobre la subjetividad. Bogotá: Universidad de la Salle.

Cassany, D. (2012). En-línea. Leer y escribir en la red. Barcelona: Anagrama.

Chartier, R. (2000). Entre poder y placer. Cultura escrita y literatura en la Edad Moderna. Madrid: Cátedra.

Chartier, R. (2006). Cultura escrita, literatura e historia. México: Fondo de Cultura Económica.

Constain, C., Forero, N. y Benavides, J. (2012). Modos en que las TIC reconfiguran el ejercicio de la ciudadanía: análisis comparativo de la relación entre las TIC y la ciudadanía en Bogotá y Popayán. Revista Educación y Desarrollo Social, 6(1), 91-106.

Daza, A. (2011). Visualidades discursivas: la cuestión de la imagen en dos grupos juveniles de Bogotá. Nómadas, 34, 229-240.

Deleuze, G. y Guattari, F. (1994). Mil mesetas: capitalismo y esquizofrenia. Valencia: Pre-textos.

Elias, N. (1997). El proceso de la civilización. México: Fondo de Cultura Económica.

Escobar, M. (2012). Del "proyecto de vida" al "guerreo". Avatares de la producción de subjetividades juveniles contemporáneas. En F. Rojas, G. Muñoz, y L. Corredor (Eds.), Jóvenes \& adultos. Una pedagogía del encuentro (pp. 82-93). Bogotá: Pontificia Universidad Javeriana.

Foucault, M. (1993). ¿Qué es la Ilustración? Recuperado de http://www.ram-wan.net/restrepo/diferencia/ que $\% 20$ es\%20la\%20ilustracion--foucault.pdf

Foucault, M. (1996). Tecnologías del yo. Barcelona: Paidós.

Galindo, L. (2012). Política, juventud e Internet: transformaciones y perspectivas de comprensión en América Latina. Utopía y Praxis Latinoamericana, 11-30.

Garcés, Á. (2011). Juventud y comunicación. Reflexiones sobre prácticas comunicativas de resistencia en la cultura hip hop de Medellín. Signo y Pensamiento, XXX (58), 108-128.

García Canclini, N. (2008). La globalización: ¿productora de culturas híbridas? Recuperado de http:// www.grupodec.net.br/ebooks/

LaGlobalizacionProductoraGarciacanclini.pdf

Giddens, A. (1995). Modernidad e identidad del yo. El yo y la sociedad contemporánea. Barcelona: Península.

González, B. (1994). Escritura y modernización: la domesticación de la barbarie. Revista Iberoamericana, 60(166), 109-124.

Herrera, M. (2013). Educar al nuevo príncipe: ¿asunto racial o de ciudadanía? Bogotá: Universidad Pedagógica Nacional.

Kant, I. (2011). ¿Qué es la Ilustración? España: Alianza Editorial

Larrosa, J. (2003). La experiencia de la lectura. Estudios sobre literatura y formación ( $1^{\text {a }}$ ed.). México: Fondo de Cultura Económica.

Lazzarato, M. (2006). Políticas del acontecimiento. Buenos Aires: Tinta Limón.

Lipovestky, G. (2002). La era del vacío. México: Anagrama.

Martín-Barbero, J. (2003a). De los medios a las mediaciones. Comunicación, cultura y hegemonía. Bogotá: Convenio Andrés Bello.

Martín-Barbero, J. (2003b). La educación desde la comunicación. Colombia: Norma.

Mejía, M. (2004). La globalización educativa reconstruye el sujeto de la modernidad. En M. Laverde, 
G. Daza y M. Zuleta (Eds.). Debates sobre el sujeto. Perspectivas contemporáneas (pp. 149-177). Bogotá: Universidad Central -DIUC, Siglo del Hombre.

Mouffe, C. (1999). El retorno de lo político. España: Paidós.

Muñoz, G. (2007). La comunicación en los mundos de vida juveniles. Revista Latinoamericana de Ciencias Sociales, Niñez y Juventud, 5(1), 1-18.

Ong, W. (1987). Oralidad y escritura. Tecnologías de la palabra. México: Fondo de Cultura Económica.

Piscitelli, A. (2009). Nativos digitales: dieta cognitiva, inteligencia colectiva y arquitecturas de la participación. Buenos Aires: Santillana.

Rama, Á. (2004). La ciudad letrada. Santiago de Chile: Tajamar Editores.
Rodríguez, X. (enero-abril, 2013). Bloqueo mediático, redes sociales y malestar ciudadano. Para entender el movimiento español del 15-M. Palabra Clave, 45-68.

Rueda, R. (2011). De los nuevos entramados tecnosociales: emergencias políticas y educativas. Folios, 33, 7-22.

Rueda, R. (2014). (Trans) formación sociotécnica, subjetividad y política. Pedagogía y Saberes, 40, 11-21.

Serres, M. (2013). Pulgarcita. Argentina: Fondo de Cultura Económica.

Sibilia, P. (2008). La intimidad como espectáculo. Argentina: Fondo de Cultura Económica.

Sibilia, P. (2012). ¿Redes o paredes? La escuela en tiempos de dispersión. Buenos Aires: Tinta Fresca.

Woolf, V. (2012). Una habitación propia. España: Alianza Yannuzzi, M. (2000). Crisis de la Modernidad. La Trama de la Comunicación, 6, 1-23. 